\title{
La muerte como presencia en la obra de Griselda Álvarez'
}

\author{
Death as a Presence in the Work of Griselda Alvarez
}

\author{
SILVIA QUEZADA CAMBEROS \\ Universidad de Guadalajara \\ México \\ silvia.camberos@csh.udg.mx
}

(Recibido: o9-o6-20I6; aceptado: IO-I2-20I6)

Resumen. La literatura de Jalisco pocas veces considera la obra poética de Griselda Álvarez (Guadalajara, 1913), debido a que su actuar público la relaciona con el estado mexicano de Colima, del cual fue gobernadora entre los años 1979-1985. Estas páginas realizan un seguimiento retórico al tópico de la muerte en sus versos, temática no considerada hasta el momento en estudios previos; considera el seguimiento de los seis primeros títulos de su producción, por ser éstos anteriores a su gestión pública, tiempo sin ataduras para el ofrecimiento de un discurso social con mayor libertad expresiva. Es pertinente aclarar que durante su ejercicio en el poder, Álvarez no escribió título alguno. La notoriedad de Griselda Álvarez como poeta había alcanzado algunas cimas antes de su gubernatura, como lo confirman los libros Anatomía superficial y Estación sin nombre. La escritora se distinguió por utilizar el formato del soneto, así como el tema erótico en su trabajo. La muerte, de acuerdo con la taxonomía de Merlin H. Forster, es una presencia viva en su verso, y la argumentación el arma retórica de su preferencia.

Palabras clave: escritoras mexicanas; poesía femenina; erotismo literario; literatura hispanoamericana.
Abstract. The poetry of Griselda Alvarez (Guadalajara, 1913) is rarely considered alongside literature from Jalisco, since her public action is related to the Mexican state of Colima, where she was governor from 1979-1985. This paper rhetorically examines death in her verse, a topic that until now has not been considered in previous studies. It tracks the first six titles of her production, since they were prior to her holding public office. During this time, there were no prohibitions imposed upon her social discourse, providing her with a greater freedom of speech. It is pertinent to clarify that during her public administration, Alvarez did not write anything. $\mathrm{Ne}-$ vertheless, Griselda Alvarez's reputation as a poet had reached some peaks before she took office, as confirmed by the books Anatomía superficial and Estación sin nombre. This writer is distinguished by her use of the sonnet, as well as the erotic themes in her work. According to Merlin H. Forster's taxonomy, death is a living presence in her verse, and argument is the rhetorical weapon of her preference.

Keywords: mexican women writers; female poetry; literary eroticism; hispanic american literature. \footnotetext{
I Para citar este artículo: Quezada Camberos, Silvia (20I7). La muerte como presencia en la obra de Griselda Álvarez.
Alabe 16. [www.revistaalabe.com]

DOI: IO.I5645/Alabe2OI7.I6.7
} 
Era cálida y suave, era culta e inteligente, y además era una gente que no tenía pretensiones de diva. María Luisa Mendoza

\section{Introducción}

I. La celebración del primer centenario del nacimiento de la poeta Griselda Álvarez (I9I3-20I3) se desarrolló en los estados de Colima, Jalisco y la ciudad de México. La Sala Manuel M. Ponce del Palacio de Bellas Artes fue el sitio justo para un espectáculo dirigido por Miguel Sabido, intitulado Las llamas del incendio, obra que incluyó la lectura en collage de unidades tonales de los poemas de la autora por parte de cuatro destacados actores.

En el Teatro Hidalgo, de Colima, se llevó a cabo la función de danza contemporánea Letanía de Amor, que incluyó el obsequio a los asistentes del libro Anatomía superficial, texto que causó revuelo en las conciencias de su tiempo (I967) por hablar del erotismo y la carne, sin ambages. El Museo de la Ciudad de Guadalajara conmemoró los cien años con una mesa redonda en torno a su vida y su obra, documentada en la revista Ahuehuete del Seminario de Cultura Mexicana, agrupación a la cual perteneció Griselda Álvarez. Habrá de decirse que no fueron los únicos homenajes, quizá el más importante fue el hecho de haberse reunido en un solo volumen toda la crítica, prólogos, entrevistas y reseñas de su andar por el verso, y las letras impresas.

Fueron tres las geografías principales de su actuar: la educación, la literatura y la política, disciplinas todas donde no desmereció su afán. Sin alardes de género, Álvarez pudo ocupar una curul en el Senado de la República, en un hecho inusitado para su época, cuando el poder siempre tuvo como adjetivo calificativo el ser masculino. Sin pretensiones mercadotécnicas, su estética la coloca en el siglo XXI como una sonetista de primera línea.

II. La familia de Griselda Álvarez procede del estado mexicano de Colima, sitio donde pasó algunos años en la hacienda de San Juan de Chiapa, propiedad de su padre; luego emigró a Guadalajara a estudiar en muros monjiles, con las Teresianas, para continuar sus estudios en la ciudad de México, donde se graduó como maestra de instrucción primaria superior. Interesada en los asuntos del lenguaje se cultivó en la Escuela Normal de Especialización. Años más tarde, ingresó a la Facultad de Filosofía y Letras de la Universidad Nacional Autónoma de México (UNAM), donde encontró la vereda exacta para hacer surgir su palabra, recreando nuevos mundos.

Una de las influencias más acusadas en la poesía de Griselda Álvarez es Sor Juana Inés de la Cruz. A la celebrada escritora le dedica unas palabras preliminares en la edición 
de un folleto impreso en el marco del Año Internacional de la Mujer, donde expresó acerca de la poeta novohispana: "Todos sabemos que gran parte de la obra fue anecdótica" (Álvarez, 1975: 5). Pareciera que ese juicio pudiera aplicarse a su propia poesía, dado que los versos de Griselda, escritos desde la primera persona, pueden comunicarnos por igual aspectos de una biografía.

El lector se deja llevar por la ilusión y no cree necesario buscar un curriculum vitae para conocerla, pues ella misma nos expresa: "Nací para vivir. Para el dispendio. / Para salvar la risa de la espina, / para aumentar con llamas el incendio" (Álvarez, I972: II9). En esa vida intensa pudo más la rosa que la espina, donde buscó vivir como protagonista fiel y humana de sus voces poéticas.

Griselda Álvarez se casó con Antonio Delgado Espinoza, médico que conoció al ingresar a trabajar en un laboratorio. Tuvo un hijo, Miguel. Fueron años de crianza y de trabajo como profesora y en papel de funcionaria. Luego se quedó viuda. Mucho más tarde comenzó a publicar sus versos, el primer libro es de 1956 y lleva por nombre $C e$ menterio de Pájaros, tenía para entonces 43 años de edad, y la estación florida comenzaba a alejarse de su cuerpo, pero germinaba la génesis de su talento y sensibilidad poéticos llenos de lozanía.

Vinieron los libros poco a poco, Dos cantos, Desierta compañía, Letanía erótica para la paz, Anatomía superficial, Estación sin nombre. Su trabajo se divulga y la hace ganar en reconocimiento. Los años noventa la etiquetan como una escritora mexicana significativa, con ediciones de 20,0oo ejemplares en circulación. Sus tópicos en torno a la vejez y al erotismo la posicionan en el sitio que ganó su poesía de modo natural, porque la voz reflexiona sobre el gozo y la estación de despedida.

Pocas escritoras han dedicado líneas tan optimistas para la senectud, en Sonetos terminales Griselda da una lección de entereza admirable en su poema intitulado "Desayuno":

Si es que me siento sola, no me importa [...]

Tengo amigos y amigas; más de alguno,

por teléfono a veces me resiste.

Espanto algún recuerdo inoportuno

como si fuera mosca. Y si persiste,

le invito un poco de mi desayuno.

Sé que estoy sola. Pero nunca triste (Álvarez, I997 b: II).

Los versos de Griselda Álvarez respiran energía, humor e inteligencia. Es una poeta mexicana distinguida con una cualidad preponderante: la finura y exactitud de su artificio.

Es necesaria una reflexión sobre su andar político antes de introducirnos en el análisis de sus versos, para justipreciar a la mujer completa en su oficio de palabras públicas y privadas. 
III. Es desafortunado que el camino de una mujer en los campos de la política y el arte sigan siendo materia de admiración por el simple hecho de ser mujeres, debido a la ancestral costumbre de relegar al género femenino de ambos campos, y que, a pesar del talento y de la dignidad con la que ejercen ambas tareas, sea todavía imposible dejar de aunar a la difícil condición de ser una persona extraordinaria, la dificultad de haberlo hecho desde la condición femenina.

En el mundo del arte, Griselda Álvarez dejó una marca indeleble, que pasado el tiempo adquirió una dimensión más justa al ser admirados los valores estéticos de su obra y al ser ésta evaluada con los mismos parámetros que los demás escritores, independientemente de su género. En su carrera política, por otra parte, todavía es difícil separar la cuestión del género, en cuanto al reconocimiento de la igual capacidad para gobernar de hombres y mujeres, a quienes asiste la misma voluntad de servicio, y el hecho de afrontar los mismos retos.

Sobre los hombros de Griselda Álvarez había mucha historia; la carrera política de su padre, también gobernador del estado de Colima, el linaje político que se remontaba hasta su bisabuelo, también gobernador de la entidad y miembro del Constituyente en tiempos de la Reforma; la fuerza de los apellidos, que sin lugar a dudas fue al mismo tiempo bendición y carga, puesto a que había que demostrar estar a la altura de lo que de ella se esperaba, al mismo tiempo que ser ella misma y demostrar el mérito propio.

En su libro Cuesta arriba, con un tono literario e íntimo, en primera persona, Griselda Álvarez da cuenta de su vida, de su tiempo, de su familia y de su tierra; en él muestra preocupaciones que revelan a una persona consciente de los problemas y de los retos del futuro, para Colima, para México, para el mundo. Cuestiones que no estaban de moda y sobre las que no se debatía seriamente en el no tan lejano año de I979, cuando le tocó contender, y ganar por abrumadora mayoría, la gubernatura de Colima.

Educar para progresar no fue, para la gobernadora, sólo un eslogan, sino un compromiso que se hizo patente en la construcción de infraestructura, en el reforzamiento del sistema educativo, en la protección de las áreas verdes, a las que añora en sus memorias, preguntándose si desaparecerán, mientras cuenta que los árboles de ébano y sándalo se acabaron pues, se usaban para hacer carbón y "las tortillas más caras del mundo y las mejor perfumadas" (Álvarez, I992:25).

Pero quizá sea injusto abordar su aportación a la vida política nacional a partir de su triunfo más evidente, que fue de ser la primera gobernadora de un estado en México, y sea más pertinente echar una mirada a su trabajo en otras dependencias, como su brillante paso por el Senado de la República; su promoción al deporte como parte de una vida ciudadana sana, cuando fue Jefa de Prestaciones Sociales en el Instituto Mexicano del Seguro Social; su Dirección General de Acción Social en la Secretaría de Educación Pública o su interés sincero y permanente por la incorporación igualitaria de mujeres dentro de las universidades, que la llevó a ser la Presidenta Honoraria Vitalicia de la Federación de Mujeres Universitarias. 
Pero quizá debiéramos ir aún antes, a su incorporación al Partido Revolucionario Institucional, que al paso del tiempo ha perdido prestigio por acciones de administraciones posteriores, descrédito que no debe arrastrar consigo a la gente pensante y comprometida que militó en él en el pasado, y sin olvidar que hace no mucho tiempo era la única opción real para ingresar al servicio público.

Griselda Álvarez, a pesar de la alcurnia política de su familia, cuenta esa afiliación con palabras sencillas que denotan una humildad poco acostumbrada en la clase política nacional:

Leí meticulosamente la Declaración de Principios, el Programa de Acción y los Estatutos.

Me gustaron estos documentos básicos. Comparé lo que había leído con alguna otra documentación de algún otro partido.

Llegué al PRI a pedir trabajo sin remuneración. Me aceptaron y me dieron credencial, Desde entonces, durante varias elecciones, fui nombrada en las casillas escrutadora o representante de candidato o presidenta o secretaria o simplemente presté la cochera de mi domicilio para instalación de casilla o el jardín de mi hogar para ofrecer un desayuno en favor del candidato a diputado en turno por el distrito XXII (Álvarez I992:68-69).

Esta pequeña narración es una muestra del carácter de Griselda Álvarez, por demostrar vocación de servicio; por validar que se fue abriendo camino por méritos propios y una convicción firme en su quehacer ciudadano; por demostrar iniciativa propia; por dar la imagen de una mujer que entendía a la acción política como una responsabilidad ineludible y que se desempeña sin soberbia ni aspavientos. Su carácter también queda demostrado en el pasaje en que cuenta las circunstancias en las que compitió por la gubernatura muchos años más tarde:

REPITO que algún día caí en la necesaria reflexión: si me atacan es porque ven en mí la posibilidad de "llegar". En otras palabras y cambiando un poco el conocido entimema: "Me pegan, luego existo".

En rigurosa meditación de "mi caso", a quien le debo el primer empujón es al ex senador y coronel Antonio Salazar Salazar. Lo digo sin resentimiento. ¡Qué va! Con sus embestidas subterráneas, constantes, me hizo más conocida en el medio político. Me abrió los ojos, como se dice. Me ayudó en sentido contrario" (Álvarez 1992:83).

En el capítulo titulado ¿Dedazo?, Álvarez admite haber jugado "a la tímida”, en su candidatura, permaneciendo en un recatado segundo lugar hasta el momento de dar el gran salto, porque sabía que no sólo estaba hablando por ella, ni representando a sus partidos (no hay que olvidar que también fue nominada por el PPS) y a su ideología, sino que 
representaba una oportunidad histórica para las mujeres en la política. Estrategia, visión de futuro, compromiso social. Todo eso demostró Griselda Álvarez en su momento, y no descubrió nada nuevo para la política, sino que dejó en claro que la política es un juego que es y debe ser sin prejuicio de género.

Lo extraordinario no tiene género, pero lo mundano sí, porque nos impide ver más allá de faldas y pantalones. Griselda Álvarez fue extraordinaria en cada una de las cosas que realizó, y fue una fuerza de impulso para llegar a la igualdad de condiciones que permitan a todos lograr lo extraordinario, sobrepasando la estrecha visión de los estereotipos. La igual participación, la igual inclusión, el mérito también igual, son componentes tan indispensables en la democracia que, sin ellos, no es real, sino una simulación.

Griselda Álvarez: política, maestra, literata, ideóloga, ciudadana comprometida, servidora pública, parteaguas, pionera, senadora, gobernadora, ejemplo. Desempeñó todas esas funciones sociales con probidad y excelencia en un tiempo en que no se admitía la capacidad igual de la mitad de la población del país. La muestra dada por ella debe iluminar el camino a la todavía lejana igualdad de derechos y de representación en un México que no sólo está en condiciones de necesitar a sus mejores hombres, sino la de todos sus mejores ciudadanos.

IV. El soneto fue el mejor vehículo de expresión literaria de Griselda Álvarez. Lo entendía en su acepción primigenia: "del italiano sonetto, diminutivo del suono "son, sonido" (Corominas, I983: 303). La composición poética de catorce versos distribuidos en dos cuartetos seguidos de dos tercetos (Moliner, 2007: 2760) ocupó el primer lugar entre sus herramientas de trabajo, quizá porque un soneto, lo sabemos, es una especie de discurso miniaturizado donde: "los cuartetos plantean y desarrollan, un poco, el asunto. En los tercetos se obtienen conclusiones y el último verso, sobre todo esto, debe ser remate sonoro y contundente" (Hiriart, 2003: IO8).

Es Griselda quien vuelve a poner en circulación de modo principal ese formato, en un tiempo de predominancia del verso blanco -se caracteriza por tener una métrica regular y carece de rima-, en un cuidadoso desfile de ritmos a manera de una bien afinada orquesta. Con ese formato se construyó la obra a partir de Cementerio de Pájaros (I956), primero de sus libros, texto donde se alza el gran tema de Griselda Álvarez, el encuentro de los cuerpos.

Es falso que ella introdujera "el elemento erótico en la poesía escrita por mujeres”, como afirma Francisco Blanco (Álvarez, 2007: 25), uno de sus entusiastas editores, pero sí pulió con finura esa veta. Su ojo poético permite vislumbrar el erotismo, recreado en el contacto de dos cuerpos que se fusionan, como una acción enteramente humana con un pasado de placer instintivo, una imaginación divina, pero sobre todo un juego de sensibilidades.

Cabe mencionar que el erotismo ha sido teorizado por múltiples científicos, pues engloba lo físico, social y lo cultural. Para George Bataille (I988) el erotismo es un dispositivo complejo, porque abarca diversos componentes que van desde lo subjetivo, lo 
social, la bioquímica tanto de los olores como del gusto, hasta la posición y el control de todos los sentidos, de una atracción sexual.

Salvador Novo creyó ver en los poemas de la mexicana el aliento de Berta Singerman, declamadora argentina cuya voz apasionada conmovió a toda una generación modernista (Álvarez, I972: 9), de tal modo que sus matices eran eco de poetas como Delmira Agustini, Juana de Ibarbourou o Gabriela Mistral. Lo cierto es que la expresión femenina en México había logrado en los años cincuenta una voz clara y firme, con trabajos afiligranados una década antes, por Rosario Castellanos y Rebeca Uribe, versificadoras del postmodernismo.

El tema de la fusión amorosa se aposentó con Letanía erótica para la paz (I963), título que suena a poema sinfónico, texto preñado de musicalidad y reiteraciones. La pareja ancestral se erige victoriosa en un mundo creado por la humanidad para que sus cuerpos se encuentren. Su unión permite que la pareja humana siga generando comprensión, ternura y complacencia mutua en su presente, pasado y futuro perennes. La composición puede resumirse en sus primeros cuatro versos:

Amado, ven, asómate al principio del mundo,

somos los mismos, mismos de hace cincuenta mil años.

Somos aquéllos, éstos, los de allá, los de siempre

y los que han de seguirnos y los que vendrán luego (Álvarez, I997 a: 9).

El erotismo sutil, pero vehemente, del extracto del poema permite la expresión variopinta de manifestaciones que promueven el encuentro de los cuerpos.

El compositor Blas Galindo compuso la cantata del mismo nombre en r965, con el interés de describir las escenas eróticas mediante los acordes, impulsando emociones y sentimientos en el espectador, más allá de las palabras mismas. La letanía fue de los textos favoritos de su autora, quizá porque allí plasmó la vitalidad del sentimiento del amor, siendo la demostración más íntima de fenómenos corporales percibidos como deseos sexuales, excitación que por lo general se identifica con el placer físico, sensorial y mental.

En Anatomía superficial (1967) organiza una serie de sonetos que describen el cuerpo masculino, en aparente detalle va nombrando a la frente, ojo, nariz, oreja, boca hasta llegar a la piel profunda del ser amado:

Este libro constituye una muestra de poesía amorosa única en nuestras letras y que no le he hallado otro antecedente en la poesía universal, que el de los "Blasones” de la Escuela de Lyon en el siglo XVI, iniciados y concluidos por Clemente Marot y escritos por un grupo de grandes poetas, cada uno de los cuales tomó por tema una parte del cuerpo de la mujer (Álvarez, I994: XIII).

En esta obra el sustrato, es decir, el hilo conductor es el conjunto de señales urdidas de conmovedores sentidos, el cual mantiene al lector fijo a la contemplación, de 
efímero desarrollo, de su ser erótico, el cual está al otro extremo del campo poético.

El sexto de sus libros de poesía: Estación sin nombre (1972) fue impreso y distribuido en Barcelona, con un tiraje de 3,ooo ejemplares, con el ánimo de explorar otras sensibilidades. El título se refiere a un espacio temporal que no corresponde a ninguno de los conocidos, sino que representa ese tiempo en que somos cuando estamos enamorados: Una quinta estación. Esas son las páginas de la plenitud amorosa, de la felicidad de estar viva, de la contemplación del espectáculo que transcurre día a día ante la voz lírica.

El erotismo es por tanto, filón vital de su producción antes que callara la voz de modo temporal para dedicarse a la política. Fue el tema de muchos de sus poemas, su ejercicio literario del deleite, su gusto de cotidianeidad, la decisión propia para plasmarla en herramienta de poder, de expresar y de autosatisfacción. Cabe mencionar que ella fue una mujer que pudo vislumbrar lo bello del interior del ser humano, pero también tocó algo del afuera, de lo colectivo, de lo mexicano, de su nación viva y convulsa por distintos derroteros negativos.

Eros campeó en las publicaciones de Griselda Álvarez, pero también, un tópico igualmente importante, el de su poesía civil dedicada a México. En 1959 había publicado el libro Dos cantos, relacionado con su patria, nación que contemplaba desvalida. La comparaba allí con un niño que resiste los embates del hambre sin más traje que una sonrisa rota, una cara mirando al Sol en búsqueda de arropo.

La amalgama de tristeza y alegría coloca en la balanza de los versos el pesar y el optimismo, pero es su ánimo el que inclina la báscula hacia la certidumbre del querer salir avante, haciendo uso de las ideas, de la acción social. Duele la provincia de sus años mozos, y no reconforta el humor que tiñe a los temas más serios de la patria: "donde todo lo trágico se ha vestido de broma, donde la vida vale un albur de baraja” (Álvarez, I98I: 23). Es la juventud de la nación la que permite alzar la voz en perspectiva de triunfo.

Cabe mencionar que la escuela del nacionalismo en las Artes en México ya no era de usanza habitual. No obstante esto, había dejado algunos fundamentos como el amor a la patria por sobre muchas otras cosas, principio a guisa del bíblico, con el cual Álvarez indagó en aquellas huellas que constituían por siglos a la cultura mexicana, y por lo tanto a la memoria patria que constituyó a fortalecer su poesía y su fuerza integradora y simbólica de su hacer artístico y político.

V. Un tema significativo en la escritura de Álvarez es el mortuorio, quizá el segmento de la vida humana menos conocido. Nadie tiene vocación para acceder a éste, antes se le teme. La figura de la muerte se ha poetizado para poder ser entendida, o por lo menos asimilada con tersura. Es una pregunta esencial que ha quedado irresoluta. Se la concibe como verdad ineludible, como el momento de dejar de ser uno mismo para perderse en lo desconocido.

No hay que ser filósofo para preguntarse qué es la muerte y cómo se enfrenta. La figuración de la muerte es un símil y una metáfora. Es tan oscura como la noche, dice el lugar común, y es noche prolongada de huesos que termina en nada. Gramaticalmente es 
una fémina, y en función de sustantivo, una abstracción. ¿Cómo la representan entonces los poetas? La analogía remite a frialdad, a rigidez. La inmovilidad y la descomposición son instantes sucesivos en ella. Para la mayoría de los escribas, la muerte es la compañía inevitable, la sombra, el destino temido, el futuro del que ninguno puede escapar.

El analista Merlin H. Forster llevó a cabo una taxonomía de la muerte en la poesía mexicana que no ha vuelto a repetirse, ningún otro se ha ocupado de encasillar los modos de escribirla. De acuerdo con el estudioso la muerte puede representarse: a) en tono leve, popular o grotesco; b) como inmortalidad; c) a modo de elegía o epitafio; d) como vida eterna; y e) como presencia en la vida (I970).

La atenta lectura de más de un centenar de poemas fúnebres provocó que Forster compusiera su libro intitulado La muerte mexicana en la poesía, donde la óptica del humor, tristeza, aspiración a la vida eterna o la resignación campean. Entre los mexicanos, la tradición de estos textos decisivos comienza con "Como una pintura nos iremos borrando" de Netzahualcóyotl, poema nahua inserto en la valoración de la vida y su belleza, enmarcada en flores y cantos; y alcanza cimas con composiciones tales como Ese espacio, ese jardín de Coral Bracho, sin olvidar "La muerte del Mayor Sabines" de Jaime Sabines y/o "Décima Muerte" de Xavier Villaurrutia.

El análisis de contenido de cada uno de los poemas de Griselda Álvarez nos lleva a interpretar las formas discursivas propuestas por la lingüística general: vemos entonces propuestas narrativas, descriptivas, expositivas y argumentativas, pero se pueden incluir aquéllas biográficas y emocionales. Desde el punto de vista narrativo, los poemas proponen una circunstancia y la llevan a término de manera íntegra. Cuando lo que interesa es la descripción se hace énfasis en los detalles, se pormenoriza la figuración del objeto hasta sus últimas consecuencias, en una especie de sitio.

Los poemas expositivos usan la sugerencia como instrumento vital, permiten entrever aquello que no se dice, pero se propone. Cuando el discurso es argumentativo, quien lo profiere no sólo es expositivo, sino que va mostrando ángulo tras ángulo cual procede, quien desea demostrar una verdad, un pensamiento irrefutable. Dicho discurso argumentativo es el más utilizado por Griselda Álvarez, como se demuestra en el análisis llevado a cabo en estas páginas.

La propuesta biográfica refiere a aquellos momentos donde la poeta abordó aspectos de su vida personal como el nombre lo apunta, pero la llevó a un nivel de otredad enfrentándose con su propia persona, familia y ser poético. La compartió con sus allegados literarios, lectores y consigo misma a través de sus trazos versificados compases e íntimos; esta propuesta, y todas las otras, se permearon por la edificación de diligentes emociones, las cuales fueron constituidas por sus voces poéticas que sensibles relataron sus contextos individuales y aquellos colectivos.

Habrá de recordarse que el estilo de un escritor se conforma por los elementos que definen a una persona, por su: "modo de ser, la psicología y la sensibilidad, el sentido de los valores, gustos y aficiones, los conocimientos y la educación recibida, el mundo circundante" (Fernández Pelayo, ı98ı: ı2); sus escritos se constituyen por aquellos fac- 
tores que reconoce en sus múltiples interpretaciones a una poeta de sonetos ilustrados, sensible maestría para advertir necesidades, deseos, miedos y contumacias.

VI. Si como se ha expresado, el erotismo es médula en la palabra de Álvarez, las metáforas de la muerte son recurrencia obsesiva en la escritora, la unión de los tópicos del amor erótico y la muerte son parecidos por la pérdida instantánea de conciencia, como bien lo revelara George Bataille. Cabe explicar que para la cultura francesa el orgasmo es una pequeña muerte - petite mort-, y por medio de sus artistas -algunos son: el Conde de Lautréamont, Charles Baudelaire, los poetas malditos y, sobre todo, Arthur Rimbaud dieron vida literaria a esa creencia gala acerca de la relación entre muerte y excitación sexual (Bataille, I988: I2) - lo han señalado como la esencia más profunda de lo humano.

Las antítesis vida/muerte de Álvarez son decisivas. ¿O no es cierto que el título Cementerio de Pájaros (I956), su primer libro, remite más al vuelo de las aves con su jocosa alegría que a la tristeza del camposanto? No obstante esto, el término de la vida está allí. La propia Griselda Álvarez lo anuncia: "Mi tema en general es el manejo de la muerte y del más allá, y también lo erótico. El manejo de la muerte me gana [...] A dónde vamos, qué somos, qué fuimos" (Alardín y Domínguez, 20o6: 37).

El primer soneto de Cementerio de Pájaros lleva por nombre "Primavera”, pero no ofrece en su entrada visual el conjunto verde y alado que la palabra remite por analogía. Comienza diciendo: "El invierno decreta su agonía" (5), es decir, la muerte se aposenta para transformarse en vida, es resaltar al invierno que está muriendo para dar paso al nacimiento de la primavera, que por capacidad de dar vida queda en un segundo término, lo que importa es la presencia latente de la muerte en todo ser vivo, animado e inanimado.

Cabe exponer que entre los poetas hispanoamericanos no fue habitual el escribir a las estaciones naturales del año como símiles, analogías y metáforas de vida-muerte debido hipotéticamente a que dichas estaciones no suelen ser tan drásticas en esta zona como sí en otras latitudes - quizá lo sean en Suramérica, no tanto así en México y en Centroamérica-, y con ello resaltó esa pródiga sensibilidad poético-artística que Griselda Álvarez tuvo para percibir sus contextos culturales y naturales.

La voz lírica va describiendo las estaciones del año en los verbos de la poeta, y cuando se refiere al espectáculo del otoño, el cuerpo humano desliza su sombra para darle significado al mundo: "El principio del fin. No existe el modo / de poder escapar. Hoy, más que todo / nos sentimos carroñas en potencia” (8). Concurre en su obra, como afirmara Margarita Michelena, una “...fuerza trágica del ser humano inclinado sobre su fugacidad...” (Álvarez, I979: IX). La naturaleza enmarca el gozo de estar vivo, pero esta misma profusión anuncia la debacle.

En Desierta compañía (sonetos de la tierra y del agua), publicada en ig6I, ofrece una voz madura basada en la contemplación, canta al paisaje de su infancia y en él encuentra los motivos gozosos para celebrar la vida. Un sentimiento de soledad es raíz en los tercetos, reveladores de una voz poética contrita, que lucha por no amilanarse ante el yermo de la vida, lo cual le posibilita la indagación de otros ramales para afianzarse. 
Con sonetos admirables, de tan sencillo decir que parecieran naturales, sin la forjadura del endecasílabo, ni la rima, luce la madurez pulcra del amor, aún cuando el amado se encuentre ausente, Emboscado detrás de su cintura, distante, pero siempre presente. El sentimiento de ser fugaz de esas escenas es serenado por la poesía, la cual expresa con sencillez: "En su origen crecido el polvo adhiere [...] nace, crece, también ama y se muere" (Álvarez, r980: 9). La colección de sonetos celebra a la flor, la cual se origina de acuerdo con su hipótesis en "el polvo de los muertos” (II), y aún más específico del beso caído de los niños que se marcharon para siempre, sin posibilidad de regreso.

De alguna manera, siguiendo la taxonomía de Forster, la muerte se presenta como elegía, en "Hormigas" cuando describe: "Las he visto morir, casi en la cima, /aplastadas igual, también, sin nombre" (Iz). Los insectos de "olor sonoro" causan azoro y reflexión, se ve en ellos la breve estancia en el mundo. En este libro campea la certeza de la muerte, permeada en vistosos seres vivos, como una mariposa, un pez, la rosa que ilumina el día.

La dualidad muerte-vida-vida-muerte pulsa, por tanto, constante en los poemas de Álvarez, está siempre en su visión poética, permea sus letras, su vida y su pensar acerca de la muerte, sus ideologías y sus creencias; se cuela en todo lo que ella fue, y en quien sigue siendo a través de sus palabras. La poeta aprehende la muerte, como temática literaria, desde ese coexistir cotidiano como lo perecedero donde inquiere lo mejor de las dos condiciones para poetizarlas.

Otro elemento de la naturaleza al cual impactó a la poeta fue el árbol, el cual yacía como armador de nidos, pero al mismo tiempo madera de ataúd (23). La imagen fúnebre para los gusanos de jardín sobrecoge la voz del lector en turno cuando asume que ellos serán quienes habrán de: medir en mi cuerpo, carne arriba, / la dimensión exacta de mis huesos (Ig). Ésta es la observación circundante de todo aquello que nos rodea, permanecerán algunas cosas (como el libro) pero no todo aquello que se mueve porque está vivo.

Desierta compañía es canto de libertad y conciencia de soliloquio, un trozo de tiempo robado para erigirse en fragmento de eternidad. Es declaración de dominio ante la fugacidad del ser:

Lo importante es que soy. Que hubo un segundo escogido en los siglos para hacerme, que voy feliz sobre la sal del mundo pensando que no puedo sustraerme a mi próximo fin, y en él, profundo, vivo el goce de ser sin condolerme (Álvarez, 1980: 29).

Mas esa aparente aceptación no está exenta del tono grotesco. En Desierta compañía pululan los jardines, pero en algún verso surgen los gusanos; hay hierba verde, sinónimo de frescura y también sudario; la vida es un vuelo, una cumbre gozosa, y un pozo profundo ante el próximo fin del que ninguno puede sustraerse, excepto la poesía.

La composición "Pala" reflexiona en torno a la durabilidad de los objetos. Hay 
en este poema un deseo de permanencia explícito a través de la voz, de la escritura, que aunque pueda envejecer con el paso del tiempo no deja de marcar un periodo y un espacio del cual se ha marchado, deteniéndose la presencia en el tiempo, en las cosas: "El destino breve de la rosa" (35) se contrapone al de la persistencia del libro, testigo de los tiempos. El asunto de la fugacidad de la rosa, tema perenne de la poesía, no le es ajeno.

El sustrato de la dicotomía vida-muerte lo toma Álvarez para expresar esa desconcertante inquietud por la existencia, valga la expresión, de ambos polos de la comprensión humana de sí. Es por medio de esa zozobra que la poeta levanta su voz lírica y busca en los dos extremos la razón de la conciencia del ser humano ante los fenómenos originarios (vida-muerte), quien no comprende y por ello sujeta expresiones analógicas, simbólicas y totémicas de ambos extremos está condenado a vivir y a morir de manera ordinaria.

La exaltación de la muerte, entonces, campea en los veintiún sonetos de Anatomía superficial. En cada texto donde se alude la presencia fúnebre se contrasta la visión de vida plena que ofrece el cuerpo masculino; si nombra al ojo, singular parte del cuerpo que sin lenguaje sonoro comunica, expresa que después de muerto, sigue mirando. El hombre inmóvil cuando descansa es: "aprendiz de cadáver" (7I). Pero sin lugar a dudas, el texto central de este libro permite observar el tratamiento de la muerte como presencia:

Apariencia no más. Por dentro explora

tu oscuridad, tu sal, tu vericueto,

virus, microbio, célula y espora;

sangre y podre total es tu sujeto:

la fealdad adentro te decora

y te tiembla de muerte el esqueleto (Álvarez, I994: IOZ).

El adjetivo de la Anatomía superficial se devela. El canto a la vestidura carnal es banalidad nombrada con alabanza efímera. Es "Anatomía superficial” el texto más representativo de su autoría, porque en esos renglones se ahonda el tema del erotismo con la finura que sólo una mujer cultivada en pleno, puede manejar.

Eros y Tánatos están presentes en el instante mismo del encuentro de los cuerpos, deseo y muerte fundidos en la acción efímera de una desnudez que no olvida su finitud. El discurso argumentativo busca la explicación científica y su discurso preciso, las palabras usadas son apropiadas para el ensayo médico, para la descripción anatómica, para la sintomatología, para el diagnóstico científico.

El debate de la vida y la muerte resaltan como experiencias e instituciones, pues la vida es como una fuente eterna, expone Friedrich Nietzsche (I985), que constantemente produce individuaciones y, produciéndolas, se desgarra a sí misma. De ello nace la necesidad de representar la apariencia de las cosas para salir de la realidad y alcanzar el principium indiviationis, y con ello conquistar la consumación del objeto eternamente alcanzado del Uno Primordial, donde gane la mesura de la vida a toda desmesura de la 
muerte y el deseo. He allí el punto central de lo apolíneo, explicaría Nietzsche, y despunta en su hacer poético Griselda Álvarez.

La vida cotidiana es repugnante e inútil. Por consecuente sólo el arte y la poesía harían cambiar de parecer a los seres humanos. Entonces, el coro de las voces poéticas de Griselda Álvarez es el acto salvador de las cosas y personas dicotómicas, y de sus maneras de concebir sus instantes de existencia y declive. En Estación sin nombre el lector encuentra dos poemas bastante significativos para el tema que propone este trabajo: "Vida" y"Muerte".

Hay temblor y miedo cuando la cognición de la muerte se dibuja, pero al mismo tiempo, conciencia de la transformación de la materia: “Qué aleluya volver de la ceniza, reconstruirse y nacer de nueva cuenta, volver los dos con unidad violenta” (Álvarez, I972: 2I). La voracidad del instante que consume provoca congoja, puesto que a cada segundo se acerca el luto. Sentencias como "Morir no es la gran cosa" (6o) o "nacer y morir van de la mano" (75) permiten observar esta dualidad indestructible, pero sobre todo, una filosofía serena acerca de una materia que se va repesando hasta la saciedad.

Si se intentara una definición de muerte, partiendo de Estación sin nombre, se lograría en una construcción al passim, un texto como el siguiente: Muerte es la hermana del sueño, fragua en el cuerpo los gusanos, es silencio, reposo, polvo, ceniza, pero de ella nacerá la primavera, la vida, el movimiento. No obstante esto, ambos polos se conciben en el mismo instante, pues iniciar la vida y en ese preciso momento se comienza la muerte; pareja amorosa inseparable que sostiene soplos y recuerdos. Como puede observarse, es de nuevo la argumentación lo que se expone, se parte del símil, se busca la metáfora, pero al final, es la lógica la que gana.

VII. La obra de Griselda Álvarez se concentra en I8 títulos publicados, diez dedicados a la poesía y ocho a la narrativa. De la prosa destaca La sombra niña (I965) donde las veintitrés narraciones abordan su inquieta niñez y Cuesta arriba, memorias de la primera gobernadora (I992). El cibernauta del siglo XXI puede escuchar la voz de Álvarez en la página Palabra virtual, donde se reproducen veintiuna de sus composiciones poéticas, textos cargados de reflexión y esperanza, como fue la mayor parte de su trabajo. En dicha muestra procedente del fonograma Letanía erótica, editado por la Universidad Autónoma Nacional de México (UNAM) para el repertorio "Entre voces", cupo la voz melancólica de la poeta, cuyo tono grave se asienta en el oído para convocar al alba con su revuelo de aves.

Podemos recoger diversas estampas biográficas de la vida infantil en su libro $L a$ sombra niña, como sus juegos de cartas con el bisabuelo, sus peripecias en el colegio cuando quería imponer su voluntad, así como los largos paseos por el bosque, a veces en medio de una tormenta. En esa etapa feliz, llena de descubrimientos, hubo espacios para la fatalidad como el episodio acerca de su bisabuelo, su principal compañero de juegos:

Un año, al volver a la hacienda y entrar corriendo como de costumbre al cuarto de las monturas, hallé la cama de Don Josecito muy alisada, muy bien tendida: pon- 
cho rojo y blanca almohada. Sobre ella estaba la montura de mi bisabuelo, quizá como símbolo de su religión hecha de mangana y de pial. Nadie me lo dijo. Salí de puntitas para no despertar de mi propio sueño, de mi niñez en fuga. Y subida en el árbol de la magnolia, sacudí sus hojas en sollozos (Álvarez, I999b: 20).

El sentimiento de la muerte se instaló temprano en ella. Aunque hayan querido protegerla, las circunstancias de su país le mostraron ahorcados y muertes violentas. Su padre nunca le ocultó verdades, antes bien, la enfrentó con las situaciones amargas, como lo demuestra el hecho de llevarla a mirar los cuerpos colgados de los opositores al gobierno en turno.

Quizá por ello nunca se apartó de la estampa de la muerte, y como idea fija, la revisitó innúmeras ocasiones, aún en los momentos más felices la recrea, es frecuente que mida en la balanza el peso de la parca y el tamaño de la dicha, para quedarse con los momentos de júbilo. Tal vez de ahí procedió su alegría por vivir, y ese humor inteligente que todo lo socavó, y la hizo destacar como una poeta mirífica.

La madurez de su poesía también le llegó con composiciones eróticas de intensa algarabía: "En donde un solo respirar se advierte / y compactos los dos como la rama / que sólo puede desgajar la muerte (Erótica, I999 a: 27). Es lógico que en esta obra, libro del que proceden los antepuestos versos se aposente la muerte, aunque aún no haya asomo de vejez, todo es plenitud. El amor vuelve solitarios a los amantes, que se apartan de todo para encontrarse, para dejarse morir después de la lucha por la vida, por el control de los cuerpos en movimientos y en calma constantes, es este evento una deliciosa pelea por el control por el poder, del someter por deleite.

Es oportuno insistir, antes de cerrar este apartado, que la poesía de Griselda Álvarez no fue pesimista, pero sí estuvo caracterizada por la dualidad vida-muerte, por la coexistencia de voces procedentes de ambos discursos. Al lado del sol aparece la oscuridad, de la vegetación, la poza; de la piel, el esqueleto. El cuerpo nunca fue lo suficientemente impactante en su lisura como para olvidar que da génesis a los gusanos y a la nada.

La alegoría de la vida se construyó con el paso temporal de las estaciones, por lo cual la lección primera y final la ofreció la naturaleza misma, en su constante devenir. Es notable la ausencia del sentimiento religioso, del que poco hablaría a pesar de haber sido educada en colegio asistido por monjas, e incluso haber querido ser una de ellas, en sueño juvenil nunca cumplido, pero sí concebido; lo religioso se volvió escenario de forma, no de fondo.

VIII. La poesía de Griselda Álvarez convivió con la pluma de muchas otras escritoras de Jalisco nacidas en el transcurso del segundo decenio del siglo XX. Fue maestra, como en algún momento de su vida lo hicieron autoras como Rebeca Uribe (I9II) y María Luisa Hidalgo (I9I4). Cultivó la poesía, la narrativa y el ensayo, como las dos mujeres nombradas y Olivia Zúñiga (I9IO). Al igual que Guadalupe Dueñas (I9IO) publicó en la madurez de su vida, una vez que la borrasca biográfica se había asentado. Como Beatriz 
Ofelia (I9II) su verso temprano se encuentra cargado de erotismo, aunque el tema de la muerte dominó su discurso poético. La diferencia más notable fue su activismo político, y su decisión por permanecer en las causas públicas con igual o mayor empeño que su escritura.

La mención de sus contemporáneas no tiene la intención de una referencia de género, pero la ubicación de su persona y su obra permite observar los intereses de la generación femenina de su tiempo. Entre los libros simultáneos a su decir poético se encuentran en el ámbito nacional Ruina de la infame Babilonia de Marco Antonio Montes de Oca; Los poemas de viaje de Efraín Huerta y Poesía de Rosario Castellanos. Sin embargo, la producción de Griselda Álvarez no ha encontrado la difusión ni la crítica especializada necesarias, por ello se rescata, o se trata de hacerlo, en este trabajo.

En La literatura mexicana del siglo XX de José Luis Martínez y Christopher Domínguez, la escritora es mencionada únicamente como ensayista de Agustín Lara. Reencuentro con lo sentimental (i980), y autora de "varios libros de buenos poemas convencionales” (Martínez y Domínguez, r995: 194), destacándose los veintiún sonetos de Anatomía superficial. El esfuerzo más reciente por compilar la crítica en torno a su trabajo se encuentra en Resaca del olvido: centenario de Griselda Alvarez (19I3-20I3): miradas nacionales, el cual fue coordinado en 20I4 por Enrique Ceballos Ramos, quien reunió prólogos, ensayos, entrevistas, reseñas y semblanzas en torno al trabajo de la escritora jalisciense.

\section{Conclusiones}

Es un hecho que los autores que escriben acerca de la muerte conocen el filón que trabajan: todos somos finitos, por tanto, el tema es de incumbencia general, o mejor dicho, humana. El misterio que establece la poesía de Griselda Álvarez no va más allá de la descomposición del cuerpo, con la desintegración de los huesos se reanima la naturaleza, quebrantándose de este modo el dramatismo de la finitud humana.

La revisión de cada uno de sus libros permitió observar en estas páginas el mismo tratamiento de transformación de la materia, no hubo evolución ni diferencia entre el libro publicado en 1956 -Cementerio de Pájaros- y el de 1972 -Estación sin nombre-. La voz lírica tampoco se transformó, siempre fue en primera persona y tomó las vicisitudes con ese "yo poético" que pocas veces compartió su deseo, miedo, gozo y dolor con un "nosotros". Los sustantivos clave que representan a la muerte son los huesos y el esqueleto, términos concretos, no hay voces abstractas ni términos espectrales.

La muerte como presencia en la vida hace temblar e invita a gozar con plenitud el momento presente, mientras aparece el destino final que paradójicamente es el inicio de otro estadío. No hay personificación del concepto, apenas la certeza del evento por venir. En el corpus de esta poesía no aparecen los signos del Infierno ni del Paraíso de modo dramático, hay congruencia con el proceso biológico del nacer, crecer, reproducirse y morir. 
De entre todos los tipos clasificados por Merlin H. Forster únicamente el de la existencia eterna (religiosa) no le apetece a Griselda Álvarez; hecho muy significativo en una escritora mexicana de la primera mitad del siglo XX. Pero está la burla irónica, el afán de inmortalidad, la elegía y, sobre todo, la presencia en vida de la muerte como se demostró al analizar su poesía con base en estos parámetros.

El concepto de la muerte en la poesía de la escritora jalisciense resulta ser una presencia activa constantemente, la cual busca evidenciar que la naturaleza la construye desde las dualidades -muerte-vida-, de los movimientos y quietudes emocionales y poéticas -no religión-erotismo-, de miedos y deseos -vejez-indiferencia moral-, de transcendencias y cotidianeidades en torno a sus actos; es en la poética de Griselda Álvarez la muerte un cauce imperecedero. Por tanto, el análisis de contenido y del discurso admitió concebir que la presencia más sonada es la muerte, la finalización de un estado que lo poetiza como existencia eterna. 


\section{Referencias bibliográficas}

- Alardín, C.; B. Domínguez (20o6). Retratos y autorretratos, de Griselda Álvarez a Ángeles Mastretta, México: Instituto Nacional de Bellas Artes (INBA), Consejo Nacional para la Cultura y las Artes (CONACULTA).

- Álvarez, G. (1956). Cementerio de Pájaros. México: Cuadernos Americanos.

- Álvarez, G. (1972). Estación sin nombre. Prólogo de Salvador Novo. Barcelona: Ediciones Marte.

- Álvarez, G. (1975). Sor Juana Inés de la Cruz. México: Secretaría de Educación Pública.

- Álvarez, G. (i979). Antología. Obras de Griselda Álvarez. México: Organización Editorial Novaro.

- Álvarez, G. (I980). Desierta compañía. Prólogo de Humberto Silva Ochoa. Colima: Impre-Roer.

- Álvarez, G. (I98I). Dos cantos. Segunda edición, México: Impre-Roer.

-Álvarez, G. (1992). Cuesta Arriba. Memorias de una gobernadora. México: Fondo de Cultura Económica (FCE).

- Álvarez, G. (1994). Anatomía superficial. Prólogo de Andrés Henestrosa y un soneto de Salvador Novo. Segunda reimpresión. México: Fondo de Cultura Económica (FCE).

- Álvarez, G. (I997 a). Letanía erótica para la paz. México: Instituto Colimense de Cultura/ Consejo Nacional para la Cultura y las Artes (CONACULTA) Colima.

- Álvarez, G. (i997 b). Sonetos terminales. Presentación de Jaime Labastida. México: Fondo de Cultura Económica (FCE).

- Álvarez, G. (ı999 a). Erótica. México: Universidad del Claustro de Sor Juana.

- Álvarez, G. (1999 b). La sombra niña, México: Biblioteca del Instituto de Seguridady Servicios de los Trabajadores del Estado (ISSSTE).

- Bataille, G. (1988). El erotismo. Barcelona: Tusquets Editores.

- Corominas, J. (1983). Diccionario crítico etimológico castellano e hispánico RI - X. Madrid: Editorial Gredos. 
- Fernández Pelayo H. (I98I). Estilística: estilo, figuras estilisticas, tropos. Madrid: J. Porrúa.

- Forster, M. H. (1970). La muerte en la poesía mexicana. México: Editorial Diógenes. Griselda Álvarez. Imágenes en el tiempo. (2007). Colima: Universidad de Colima.

- Hiriart, H. (2003). Cómo leer y escribir poesía. Primeros pasos, México: Tusquets.

- Martínez, J. L. / C. Domínguez (i995). La literatura mexicana del siglo XX. México: Consejo Nacional para la Cultura y las Artes (CONACULTA).

- Mendoza, M. L. (2OII). “Entre el poder y el soneto: Griselda Álvarez” en Personajes históricos del Congreso mexicano". México. Duración: 29:13 m.

- Moliner, M. (2007). Diccionario del uso del español. Madrid: Editorial Gredos.

- Nietzsche, F. (1985). El nacimiento de la tragedia. México: Fondo de Cultura Económica. 